Research Paper

\title{
Active immunization combined with cisplatin confers enhanced therapeutic protection and prevents relapses of HPV-induced tumors at different anatomical sites
}

\author{
Bruna Felício Milazzotto Maldonado Porchia ${ }^{1,2,}{ }^{*}$, Luana Raposo de Melo Moraes Aps ${ }^{1,2}$, Ana Carolina \\ Ramos Morenoํㅜ, Jamile Ramos da Silva ${ }^{1}$, Mariângela de Oliveira Silva ${ }^{1}$, Natiely Silva Sales ${ }^{1}$, Rubens Prince \\ dos Santos Alves¹, Clarissa Ribeiro Reily Rocha3 ${ }^{3}$ Matheus Molina Silva ${ }^{3}$, Karine Bitencourt Rodrigues¹, \\ Tácita Borges Barros¹, Roberta Liberato Pagni1 ${ }^{1}$, Patrícia da Cruz Souza1, Mariana de Oliveira Diniz,2,\#, Luís \\ Carlos de Souza Ferreira1 ${ }^{\square}$ \\ 1. Vaccine Development Laboratory, Department of Microbiology, Biomedical Sciences Institute, University of Sao Paulo, Sao Paulo, SP, Brazil \\ 2. ImunoTera Soluções Terapêuticas Ltda \\ 3. DNA Repair Laboratory, Department of Microbiology, Institute of Biomedical Sciences, University of Sao Paulo, Sao Paulo, Brazil \\ * Present address: Laboratory of Tumor Immunology, Department of Immunology, Biomedical Sciences Institute, University of Sao Paulo, Sao Paulo, SP, Brazil \\ \# Present address: Division of Infection and Immunity, University College London, 5 University St, Bloomsbury WC1E 6JF, London \\ Porchia, BFMM and Aps, LRMM contributed equally to this work. \\ $\triangle$ Corresponding author: Luís C. S. Ferreira. Av. Prof. Lineu Prestes, 1374, Sao Paulo - SP, Brazil, Zip code: 05508-000. Phone: +55 11 30917356. E-mail address: \\ lcsf@usp.br \\ (C) The author(s). This is an open access article distributed under the terms of the Creative Commons Attribution License (https://creativecommons.org/licenses/by/4.0/). \\ See http://ivyspring.com/terms for full terms and conditions.
}

Received: 2020.12.07; Accepted: 2021.10.19; Published: 2022.01.01

\begin{abstract}
The active immunotherapy concept relies on the use of vaccines that are capable of inducing antitumor immunity, reversion of the suppressive immunological environment, and long-term memory responses. Previously, antitumor vaccines based on a recombinant plasmid (pgDE7h) or a purified protein (gDE7) led to regression of early-established human papillomavirus (HPV)-associated tumors in a preclinical model. In this work, the anticancer vaccines were combined with cisplatin to treat HPV-induced tumors at advanced growth stages. The antitumor effects were evaluated in terms of tumor regression, induction of specific CD8+ $\mathrm{T}$ cells, and immune modulation of the tumor microenvironment. Acute toxicity induced by the treatment was measured by weight loss and histological alterations in the liver and kidneys. Our results revealed that the combination of cisplatin with either one of the tested immunotherapies (pgDE7h or gDE7) led to complete tumor regression in mice. Also, the combined treatment resulted in synergistic effects, particularly among mice immunized with gDE7, including activation of systemic and tumor-infiltrating E7-specific CD8 ${ }^{+} \mathrm{T}$ cells, tumor infiltration of macrophages and dendritic cells, and prevention of tumor relapses at different anatomical sites. Furthermore, the protocol allowed the reduction of cisplatin dosage and its intrinsic toxic effects, without reducing antitumor outcomes. These results expand our knowledge of active immunotherapy protocols and open perspectives for alternative treatments of HPV-associated tumors.
\end{abstract}

Key words: Cancer, HPV, vaccine, gDE7, immunotherapy

\section{Introduction}

Human papillomavirus (HPV) infections cause almost 570,000 cases per year of invasive cervical cancer worldwide [1]. Approximately $84 \%$ of cervical cancers and $88 \%$ of deaths caused by cervical cancer occurs in lower-resourced countries, of which $1.3 \%$ die from the disease before age 75 , in the absence of competing causes of death [2]. Cervical cancer represents the fourth most frequent cancer type and the third leading cause of cancer death in females [3], and continues to be a major public health problem 
affecting middle-aged women, particularly in less-resourced countries. Also, an increase in oropharyngeal cancer incidence rates (soft palate and uvula, tonsils, posterior pharyngeal wall, and tongue base) has been observed among the young adult population, mainly males, and mostly associated with HPV-16 [4,5].

The possibility of preventing cancer development by controlling viral infection, led to the implementation of a worldwide vaccination program for certain types of HPV, including the most prevalent oncogenic genotypes. However, these prophylactic vaccines do not benefit patients with established tumors. Also, available cancer treatments are based on invasive methods with many adverse effects and are less effective for advanced-stage cancer. Moreover, surgery and chemotherapy are the first-choice treatments for advanced or invasive cervical cancer, despite a 5-year survival rate of less than $20 \%$ in treated patients [6]. Furthermore, high doses of cisplatin, the most used chemotherapeutic agent, may negatively impact the antitumor responses in addition to inducing severe adverse side-effects [7]. In this context, new and alternative therapies are needed to improve disease control and survival rates in those patients with tumors at more advanced stages.

Different treatments are available for patients with cervical cancer. Cisplatin is often administered as a treatment, with or without radiation therapy, for stage IB2 to IVA cervical cancer. However, its use is often associated with serious side-effects such as nephrotoxicity, despite the survival rates as an adjuvant platinum-based chemotherapy [8]. Therefore, there is currently a growing interest in combined approaches based on chemo/radiotherapy and immunotherapy to treat solid tumors, and cancer therapeutic vaccines could play an important role in these settings. Over the last decade, important advances in tumor treatment were achieved by using passive immunotherapies. Monoclonal antibodies (mAbs) targeting immune checkpoints led to an intense wave of preclinical and clinical investigations that resulted in the clinical use of immunotherapy for different cancer types [9]. Taking cervical cancer into account, mAbs targeting the extracellular domains of tyrosine kinase receptors (epidermal growth factor receptor (EGFR) and insulin-like growth factor receptor (IGFR) were approved for recurrent or metastatic cervical carcinoma [10]. More recently, pembrolizumab was approved by the United States Food and Drug Administration (US FDA) for patients with recurrent or metastatic cervical cancer, or after chemotherapy for tumors expressing PD-L1. Despite the increase in overall survival rate, some studies reported relevant toxicity events related to the administration of these $\mathrm{mAbs}$ and variable clinical success rates [11].

Considering the induction of immune responses, antitumor vaccines have been used to stimulate $T$ cells to recognize and destroy tumor cells, leading to long-lasting antitumor response. Such an experimental approach defines a new immunotherapeutic concept based on active modulation of the host immune system, promoting a shift from the prevailing immunosuppressive environment elicited by the tumor growth, to productive antitumor responses. This new immunotherapeutic concept is strongly supported by activating antigen-presenting cells (APCs) such as macrophages and dendritic cells (DCs), both systemically and inside tumor masses. Our group has pursued the concept of active immunotherapy procedures, based on the use of DNA vaccines or purified recombinant proteins combined with strong adjuvants, to induce antitumor protective responses against HPV-associated tumors. Both vaccine types are based on the fusion of HPV-16 E7 oncoprotein to the herpes simplex virus 1 (HSV-1) glycoprotein D (gD). Using the experimental model based on the subcutaneous transplantation of TC-1 cells, mice immunized with the vaccines elicited systemic E7-specific $\mathrm{CD}^{+} \mathrm{T}$ lymphocytes and controlled tumors at the initial growth stages [12,13]. Here, we investigated a more potent treatment capable of controlling advanced-stage tumors using different HPV-associated tumor models.

\section{Methods}

\section{Cell culture}

The TC- 1 tumor cell line was derived from the c-Ha-ras transformed C57BL/6 lung epithelium and the HPV-16 E6 and E7 oncogenes [14]. The TC-1 LUC cell line was generated by the transfection of a retrovirus containing the luciferase gene, as previously described by Kim et al (2007) [15]. Both cell lines were kindly provided by Dr. T.C. Wu (Johns Hopkins University, Baltimore, MD, USA). TC-1 and TC-1 LUC cells were cultured in RPMI medium (Thermo Fisher Scientific, Waltham, USA) containing $10 \%$ fetal bovine serum (Thermo Fisher Scientific, Waltham, USA) and G418 (Geneticin; Merck, Darmstadt, Germany) at a final concentration of 400 $\mu \mathrm{g} / \mathrm{mL}$ and maintained at $37^{\circ} \mathrm{C}$ and $5 \% \mathrm{CO}_{2}$. On the day of tumor transplantation, cells were treated with trypsin, washed, and suspended in phosphate buffered saline (PBS) ( $\mathrm{pH} 7.4)$ at an appropriate concentration for each experiment. Only those cultures with a cell viability equal to or greater than $90 \%$ by the Trypan Blue staining method were 
considered suitable for use.

\section{Mice and TC- 1 tumor transplantation}

All in vivo experiments were carried out with 6-8 week old C57BL/ 6 mice acquired from the animal facility unit of the Department of Pathology (Faculty of Veterinary Medicine and Zootechnics) at the University of Sao Paulo (USP, Sao Paulo, Brazil) and handled according to the norms established by the Institute of Biomedical Sciences (ICB/USP) Ethics Committee (protocol number 36 in 07/28/2014; protocol number 104 in 10/03/2017). To evaluate the therapeutic efficacy of cisplatin and immunotherapy, the mice received subcutaneous (SC) inoculation with $5 \times 10^{5}$ TC- 1 cells $/ 100 \mu \mathrm{L}$ in the right flank. Tumor growth was monitored and major (D) and minor (d) diameters were measured in $\mathrm{mm}$ with the aid of a pachymeter at least twice per week. Treatment was initiated when at least one of the diameters reached 10 $\mathrm{mm}$, corresponding to an initial tumor volume (day 0 ) of $200-300 \mathrm{~mm}^{3}$, according to the formula $\left(\mathrm{Dxd}^{2}\right) / 2$. Mice were euthanized when tumor volume reached $1,000 \mathrm{~mm}^{3}$, or when at least one of the tumor diameters reached $15 \mathrm{~mm}$. The combination of cisplatin and immunotherapy was also evaluated in the intravaginal (IVAG) tumor model. In this case, TC-1 LUC cells were used to monitor tumor growth through the emission of luminescence. To coordinate the estrous cycle, tumor cell inoculation was preceded by SC administration of DepoProvera ${ }^{\mathrm{TM}}$ (medroxyprogesterone acetate; Pfizer, New York, USA) 5 days before TC- 1 cells implantation at a concentration of 3 $\mathrm{mg} / \mathrm{mL}$. Tumor cells transplantation was performed by injecting $1 \times 10^{5}$ TC- 1 LUC cells $/ 20 \mu \mathrm{L}$. From day 10 of TC-1 LUC cells transplantation, mice were monitored periodically by analyzing the luminescence emission in the IVIS Spectrum equipment (Perkin Elmer, Waltham, USA) at the Center for Research Support Facilities (CEFAP, ICB, USP). Mice were euthanized when the total flux reached $10^{10}$ photons/second.

\section{In vivo administration of cisplatin}

Cis-Diamineplatinum (II) dichloride (Merck) was dissolved in sterile saline solution for $1 \mathrm{~h}$ at $60^{\circ} \mathrm{C}$. The cisplatin solution was administered via the intravenous (IV) route through the retro-orbital plexus in amounts proportional to the body mass to obtain doses of $10 \mathrm{mg} / \mathrm{kg}$. The body weight of mice was measured twice per week and values were presented in relation to the body mass (in grams, g), or as a change in body weight considering $100 \%$ as the weight value obtained on day 0 .

\section{Mice immunization with pgDE7h DNA vaccine or gDE7 protein vaccine}

Immunization by the intramuscular (IM) route with pgDE7h was performed in a total volume of 100 $\mu \mathrm{L}$ per dose, with $50 \mu \mathrm{L}$ administered in each paw. Mice receiving electroporation were previously anesthetized intraperitoneally with a mixture of 75 $\mathrm{mg} / \mathrm{kg}$ ketamine (Ceva Santé Animale, Libourne, France) and $10 \mathrm{mg} / \mathrm{kg}$ xylazine (Ceva Santé Animale, Libourne, France). For electroporation, the electrode CUY560-5-0.5 was used, consisting of a pair of parallel fixed needles $0.5 \mathrm{~mm}$ in diameter with a space of 5 $\mathrm{mm}$ between them. The electrode was inserted into the anterior tibial muscle shortly after inoculation of the vaccine. Six electric pulses of $130 \mathrm{~V}$ each were applied with a duration of 450 milliseconds. Electrical pulses were delivered using the NEPA21 SuperEletroporator equipment (NepaGene, Ichikawa City, Japan). The therapeutic gDE7-based protein vaccine (PTN) was administered following a regimen of two SC doses, at day 3 and 7 after cisplatin treatment. Each dose contained $30 \mu \mathrm{g}$ of the gDE7 protein admixed with $50 \mu \mathrm{g}$ of the poly(I:C) (pIC; InVivoGen, San Diego, USA) adjuvant, diluted in saline solution (total volume of $100 \mu \mathrm{L}$ ), and inoculated in the right rear flank of the mice.

\section{Intracellular IFN- $\gamma$ staining}

Peripheral blood cells were collected from the submandibular plexus of mice in tubes containing 30 $\mu \mathrm{L}$ of heparin $(1 \mathrm{U} / \mu \mathrm{L})$. The cells were treated for 5 min at $25^{\circ} \mathrm{C}$ with Ack Lising Buffer (Thermo Fisher Scientific, Waltham, USA) for red blood cell rupture, and centrifuged at $600 \mathrm{~g}$ for $5 \mathrm{~min}$. The cells were incubated at a concentration of $10^{6}$ cells/well for $6 \mathrm{~h}$ at $37{ }^{\circ} \mathrm{C}$ and $5 \% \mathrm{CO}_{2}$ in the presence of $10 \mu \mathrm{g} / \mathrm{mL}$ Brefeldin A (GolgiPlug; BD Biosciences, San Jose, USA) and $5 \mathrm{ng} / \mathrm{mL}$ IL-2 (Sigma) in the absence or presence of the specific E7 peptide (amino acids 49-57; RAHYNIVTF; 300 ng/well) (GenScript, Piscataway, Nova Jersey, EUA) [16]. After that period, the cells were incubated for $30 \mathrm{~min}$ at $4^{\circ} \mathrm{C}$ with anti-CD8a antibody conjugated to fluorochrome BB515 (BD Biosciences) or APC (BD Biosciences). After permeabilization with the Cytofix/Cytoperm solution (BD Biosciences) for $10 \mathrm{~min}$ at $4^{\circ} \mathrm{C}$, cells were treated with anti-IFN- $\gamma$ antibody conjugated to PE (BioLegend) or BV421 (BioLegend, San Diego, USA) for $30 \mathrm{~min}$ at $4^{\circ} \mathrm{C}$. The cells were then suspended in PBS and examined by flow cytometry. Samples were acquired on a LSR Fortessa flow cytometer (BD Biosciences) and analyzed using the FlowJo software (BD Biosciences). The percentage of $\mathrm{CD}^{+} \mathrm{IFN}-\gamma^{+} \mathrm{T}$ cells over all $\mathrm{CD} 8^{+} \mathrm{T}$ cells was determined. 


\section{Biochemical analysis of blood samples}

Blood samples were collected three days after the end of the treatments from the submandibular plexus of each mice: on day 10 for "Naïve", "Untreated", and "1CIS/DNA and 1CIS/PNT" groups, and on day 17 for the "3CIS" group. Serum was obtained after centrifugation at 2,600 $\mathrm{g}$ for $15 \mathrm{~min}$ at $4^{\circ} \mathrm{C}$, and used to obtain aspartate aminotransferase (AST) (Laborclin, Pinhais, Brazil), alanine aminotransferase (ALT) (Laborclin), blood urea nitrogen (BUN) (Wiener Lab Group, Sao Paulo, Brazil), and creatinine (Wiener lab) levels, according to the manufacturer's instructions.

\section{Analysis of glutathione (GSH) in kidney samples}

Kidney samples were collected individually (one kidney per mice), frozen in liquid nitrogen, and stored at $-80^{\circ} \mathrm{C}$ until use. The tissue was mechanically dissociated, and homogenization was carried out with a $5 \%$ sulfosalicylic acid solution. Samples were then centrifuged at $18,000 \mathrm{~g}$ for $30 \mathrm{~min}$ at $4^{\circ} \mathrm{C}$ and the supernatant used for the analysis of GSH. The ratio between total and oxidized glutathione (GSH/GSSG) was obtained by kinetic analysis using the colorimetric method of detecting DTNB (Ellman's reagent). For the test, the 38185 Quantification kit for oxidized and reduced glutathione (Merck) was used, following the manufacturer's instructions.

\section{Cell population analysis in tumors implanted subcutaneously}

Tumor samples were collected individually, and cell suspension was obtained after mechanical dissociation and incubation with collagenase D (Roche, Basiléia, Swiss) at a concentration of 0.22 $\mathrm{U} / \mathrm{mL}$ per sample at $37^{\circ} \mathrm{C}$ for $40 \mathrm{~min}$. Then, samples were washed twice with PBS 1X (pH 7.4), filtered in a $70 \mu \mathrm{m}$ cell strainer (BD Biosciences), and resuspended in solutions containing anti-CD45-PerCpCy5.5 (BioLegend), anti-CD11c-PE (BD Biosciences), MHCII-BV421 (BioLegend), F4/80-FITC (Thermo Fischer Scientific), anti-CD86-APC (BioLegend), anti-CD11bAlexa-Fluor488 (BioLegend), anti-Gr-1-PE (BD Biosciences), CD8a-BV605 (BioLegend), and anti-IFN- $\gamma$-PE (BioLegend) $\mathrm{mAbs}$ for $30 \mathrm{~min}$ at $4^{\circ} \mathrm{C}$. For analysis of E7-specific intratumoral CD8 T cells, samples were stained with the APC-labeled $\mathrm{H}-2 \mathrm{Db}$ E7-specific dextramer (Immudex, Copenhage, Denmark), and subsequently stained with anti-CD8a-Pacific Blue (BioLegend). After two washes, cells were resuspended in PBS, acquired in a LSR Fortessa flow cytometer (BD Biosciences), and analyzed using the Flow Jo software (BD Biosciences).

\section{TC-1 cell re-challenge models}

To evaluate the antitumor memory responses and simulate tumor relapse events, tumor-free mice were reinjected with TC-1 cells 90 days after the first tumor implantation. Mice that showed complete regression of SC tumors were re-challenged with $5 \times 10^{6} \mathrm{TC}-1 / 100 \mu \mathrm{L}$ cells in the right flank. Mice that showed complete regression of intravaginal tumors were re-challenged at the same region injecting $1 \times 10^{6}$ TC- $1 \mathrm{LUC} / 20 \mu \mathrm{L}$, or in the tongue with $1 \times 10^{6} \mathrm{TC}-1$ $\mathrm{LUC} / 10 \mu \mathrm{L}$ cells. The group re-challenged in the tongue received another implantation 60 days later with $1 \times 10^{6}$ TC-1 LUC/10 $\mu \mathrm{L}$ cells. The luminescence emission was acquired using the IVIS Spectrum equipment (Perkin Elmer) at the Center for Research Support Facilities (CEFAP, ICB, USP).

\section{Analysis of the $\mathrm{T}$ cell memory response in spleen samples}

The cells were incubated at a concentration of $3 \times 10^{6}$ cells/well for $6 \mathrm{~h}$ at $37^{\circ} \mathrm{C}$ and $5 \% \mathrm{CO}_{2}$ with 10 $\mu \mathrm{g} / \mathrm{mL}$ Brefeldin A (GolgiPlug; BD Biosciences), 5 ng/mL IL-2 (Thermo Fisher Scientific), and 300 ng/well of E7 peptide ${ }^{16}$ (amino acids 49-57; RAHYNIVTF; GenScript). After incubation, cells were stained for $30 \mathrm{~min}$ at $4{ }^{\circ} \mathrm{C}$ with anti-CD8a-APC (BioLegend), anti-CD44-FITC (BioLegend), antiCD62L-BV421 (BioLegend), anti-KLRG1-PE (BioLegend), and anti-CD127-PECy7 (BD Biosciences) antibodies. After fixation/permeabilization with the Cytofix/Cytoperm solution (BD Biosciences) for 10 min at $4{ }^{\circ} \mathrm{C}$, cells were stained with anti-IFN- $\gamma$ antibody conjugated to Alexa700 (BD Biosciences) for $30 \mathrm{~min}$ at $4{ }^{\circ} \mathrm{C}$. The cells were then resuspended in PBS and examined by flow cytometry using the LSR Fortessa device (BD Biosciences).

\section{Statistical analysis}

Statistical analyses were performed using Prism software (GraphPad, San Diego, USA). Analysis was performed using one-way or two-way analysis of variance (ANOVA), and the results were confirmed through multiple comparisons by Bonferroni's test. The unpaired $t$-test was used for comparison between two groups. Survival curves were analyzed by the log-rank (Mantel-Cox) test. Values of $p<0.05$ were considered significant.

\section{Results}

\section{Combination of cisplatin and gD-based vaccines results in synergistic control of HPV-associated advanced-stage tumors with reduced toxic effects}

We previously reported the antitumor effects of 
pgDE7h and gDE7 vaccines. Optimal results were achieved when pgDE7h was delivered by in vivo electroporation [17], and when gDE7 was combined with the adjuvant pIC [18]. To improve the performance of both vaccines in advanced-stage tumors, we combined the active immunotherapies with cisplatin. For that purpose, mice were first treated with cisplatin when tumors reached $10 \mathrm{~mm}$ in diameter (day 0) (Fig. 1A). No systemic E7-specific $\mathrm{CD}^{+} \mathrm{T}$ cells were detected in mice treated with three doses of cisplatin (Fig. 1B), but showed transient control of tumor growth (Fig. 1C) and $20 \%$ of antitumor protection (Fig. 1D). In contrast, the combination of cisplatin with the DNA or protein-based vaccines promoted a significant increase in circulating E7-specific $\mathrm{CD}^{+} \mathrm{T}$ cells (Fig. 1B ), led to enhanced tumor control (Fig. 1C; Fig. S1) and complete tumor regression in $70 \%$ or $80 \%$ of the immunized mice, respectively (Fig. 1D). Under the tested conditions, mice treated with two doses of either DNA or protein-based vaccines alone, or one dose of cisplatin failed to induce tumor growth control (Fig. 1C-D). In addition, the administration of two doses of cisplatin did not control the tumor burden (Fig. S2A-C) and exhibited severe toxicity, as demonstrated by significant body-weight loss (Fig. S2D). Remarkably, the synergistic effects of cisplatin required administration of pgDE7h by electroporation or the co-administration of gDE7 and pIC (Fig. S3). Collectively, our data demonstrate that the combination of cisplatin with either DNA or protein-based vaccines led to synergistic effects regarding the effective control of advanced-stage tumors.

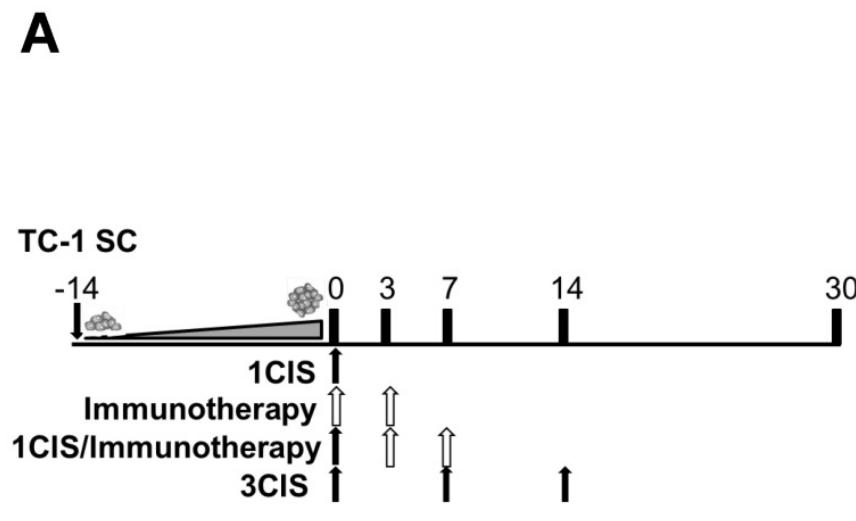

B
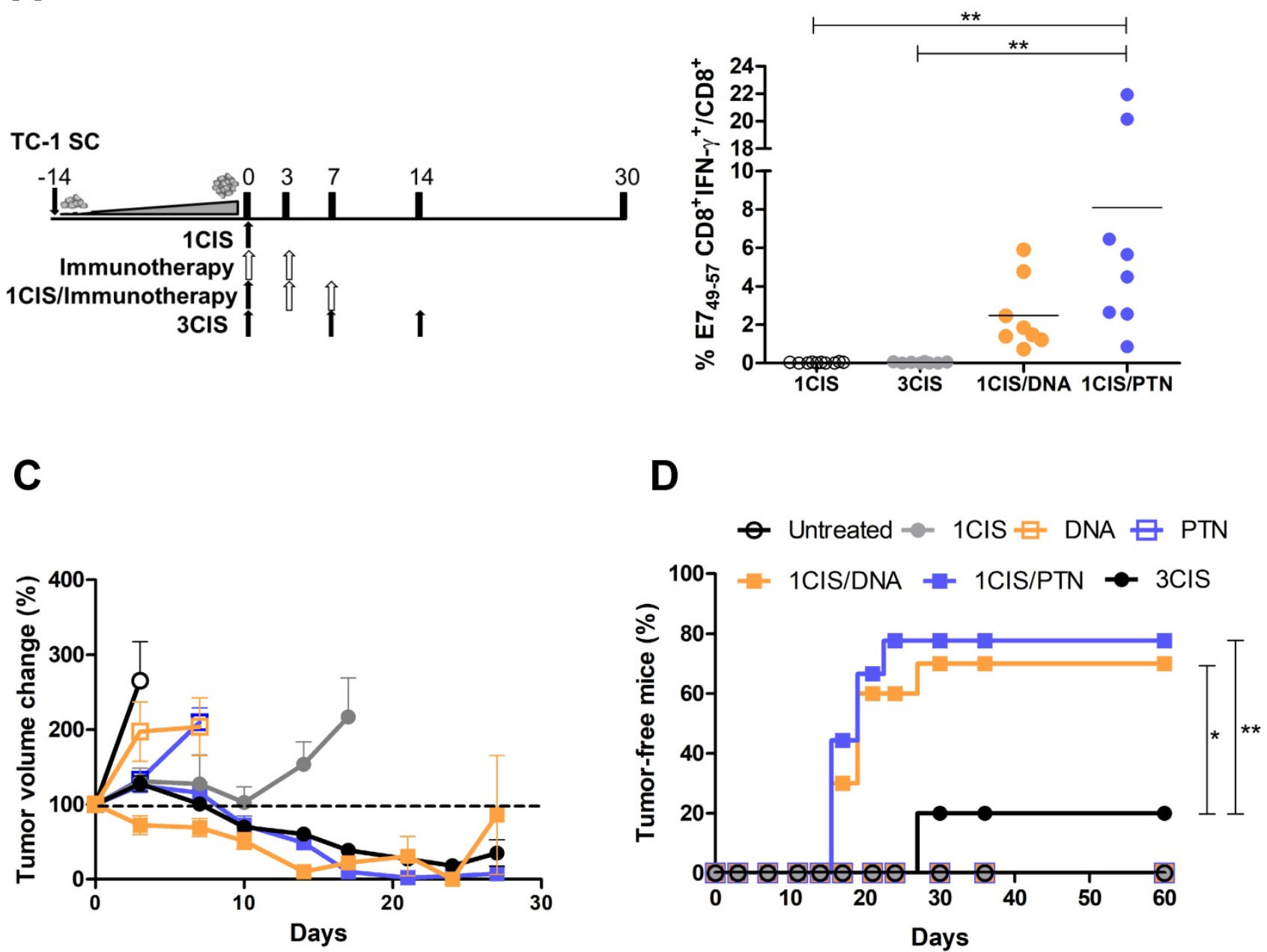

Figure 1: Combination of cisplatin and pgDE7h or purified gDE7 enhances therapeutic antitumor responses. (A) Tumor-bearing C57BL/6 mice were treated with one or three doses of cisplatin, or immunotherapy (DNA meaning immunization with PgDE7h delivered by electroporation, and PTN meaning immunization with gDE7 mixed with poly (I:C)), or the combination of both treatments (one dose of cisplatin combined with DNA or PTN). (B) Frequency of systemic CD8 ${ }^{+}$IFN- $\gamma^{+} / C D 8^{+} T$ cells after in vitro stimulation with the CD8 ${ }^{+} \mathrm{T}$ cell-specific E7 peptide (49RAHYNIVTF57) at day 14. (C) Tumor volume change of DNA- and protein-based treated mice compared to day 0 ( $10 \mathrm{~mm}$ diameter tumors). (D) Percentage of mice that showed complete tumor regression after treatment during the follow-up period. Data represent the mean $+S D$ of $8-10$ mice per group from two independently performed experiments. Statistical significance: $\left(^{*}\right) P<0.05,(* *) P<0.01$, as determined by one-way ANOVA followed by Bonferroni post hoc analysis and log-rank (Mantel-Cox) test for tumor-free data (survival curve). 
A

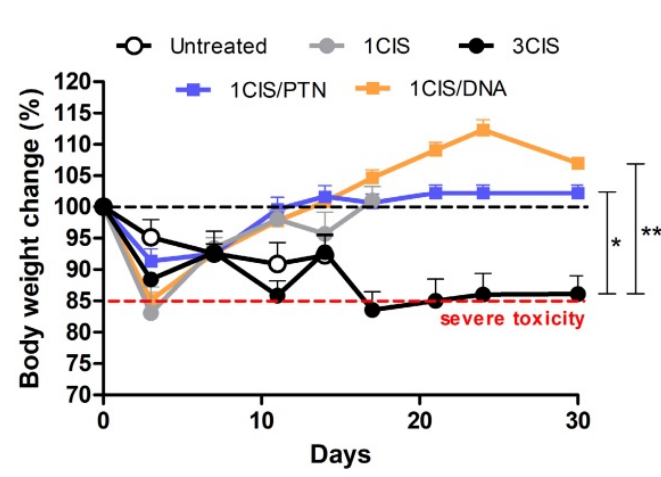

C

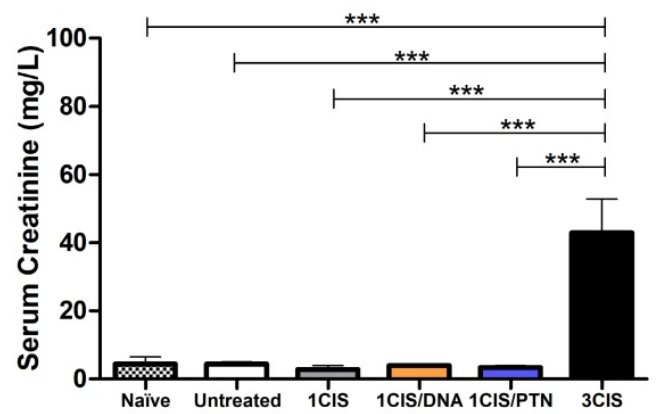

E

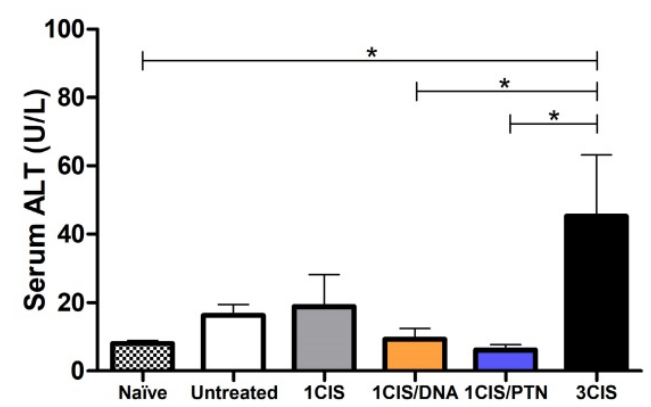

B

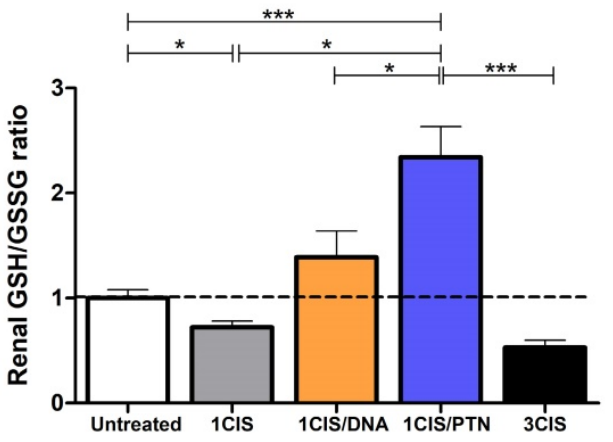

D

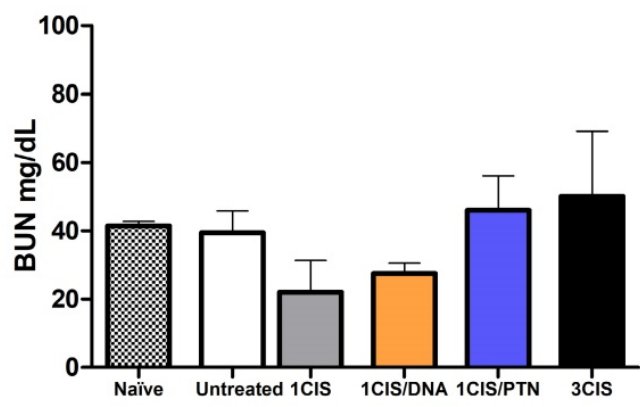

$\mathbf{F}$

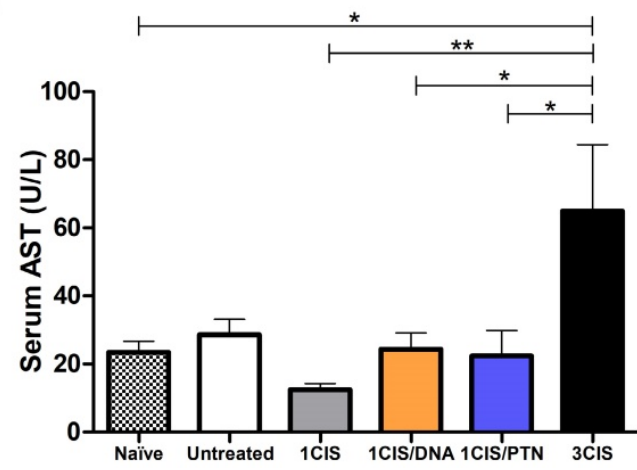

Figure 2: Combination of cisplatin and immunotherapy (pgDE7h or gDE7) reduces toxicity of anti-tumor treatment. Tumor-bearing C57BL/6 mice were treated with cisplatin, pgDE7h and electroporation, or gDE7 mixed with poly(l:C), or the combined chemotherapy/immunotherapy treatment, as presented in Fig. 1. (A) Percentage of weight loss throughout the treatment protocol (relative to initial weight on day 0 ). Non-treated group $(n=5)$, other groups ( $n=8-10)$. (B) Kidney redox status expressed as GSH/GSSG ratio assessed three days after each treatment. Serum concentration of (C) creatinine, (D) blood urea nitrogen, BUN, (E) alanine aminotransferase, $\mathrm{ALT}$, and $(\mathbf{F})$ aspartate aminotransferase, AST, obtained 3 days after each treatment. Data represent the mean +SD of 5-8 mice per group from two independent experiments. Statistical significance: $(*) P<0.05,(* *) P<0.01,(* * *) P<0.001$, as determined by one-way ANOVA followed by Bonferroni post hoc analysis.

We also investigated the acute systemic toxicity associated with the use of cisplatin and the combined chemo/immunotherapy. As demonstrated in Fig. 2A, three doses of cisplatin induced severe toxicity in mice leading to sustained $15 \%$ body weight loss (day 14). In contrast, the combination of one cisplatin dose with two vaccine doses, either DNA or purified protein, caused an initial moderate weight loss that was quickly reverted (Fig. 2A). Mice submitted only to the immunotherapy (DNA or protein) showed no significant weight loss concerning sham-treated mice (data not shown). In addition, increased glutathione
(GSH/GSSG) levels, indicative of reduced kidney damage, were detected in mice treated with the combined chemo/immunotherapy regimen, especially in mice administered with the protein-based vaccine (Fig. 2B). Conversely, mice treated with three cisplatin doses showed high serum levels of creatinine, ALT, and AST, indicative of kidney and liver damage. In contrast, treatment with one dose of cisplatin and two vaccine doses did not show any significant increase in the serum levels of these tissue damage markers (Fig. 2C, E, and F). No differences in BUN levels were found among all experimental 
groups (Fig. 2D). To confirm the toxicity induced by cisplatin, we also assessed tissue damage by histological analyses of kidney and liver of mice submitted to the different tested treatments (Fig. 3). The combined treatment induced fewer histological changes than repeated cisplatin doses in both tissues. While repeated doses of cisplatin have induced capillary thrombosis and ischemic changes in the kidneys of treated mice, the combination of a single dose of cisplatin with immunotherapy induced only mild glomerular congestion. Similarly, repeated doses of cisplatin led to reactive changes in hepatocytes and intraparenchymal hemorrhage while the chemo/immunotherapy protocol preserved the liver tissue (Table S1). Thus, we concluded that the combination of one dose of cisplatin with either pgDE7h or gDE7 allowed the reduction of cisplatin toxic effects without affecting the antitumor responses.

\section{Combined use of cisplatin and gDE7 induces tumor infiltration of immunomodulatory cell subsets and E7-specific CD8+ $T$ cells, and reduces the frequency of myeloid suppressor cells}

Further testing of the benefits and potential synergistic effects associated with the combination of cisplatin and gD-based vaccines focused on the induced immune responses in the tumor microenvironment. For these experiments, mice
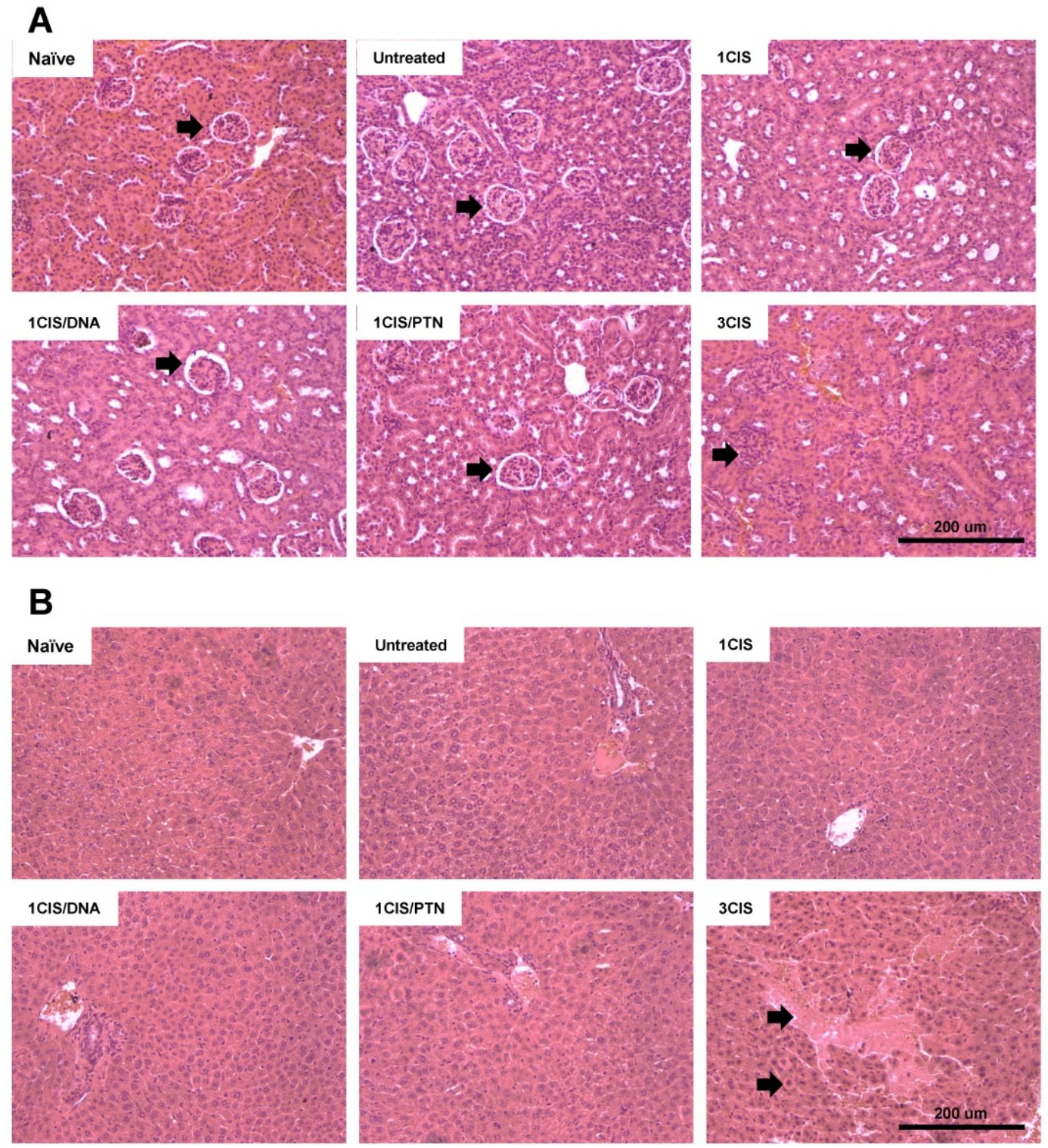

Figure 3: The combined treatment induces less histological damages than repeated doses of cisplatin. Tumor-bearing C57BL/6 mice were treated with cisplatin or the combined chemotherapy/immunotherapy treatment as previously described. (A) Hematoxylin and eosin (H\&E) stained sections of a representative kidney tissue three days post treatment $(n=3 ; 20 x$ magnification). (B) H\&E stained sections of a representative liver tissue three days post treatment ( $n=3 ; 20 x$ magnification). Histological findings (indicated by arrows) are depicted in Table S1. 
received one dose of cisplatin, the protein-based vaccine alone, or the combined treatment. Under the tested experimental conditions, mice treated with cisplatin combined with purified gDE7 admixed with pIC showed higher frequencies of intratumoral CD45 ${ }^{+}$ cells (Fig. 4A) and CD11 ${ }^{+} \mathrm{MHC}-\mathrm{II}^{+} \mathrm{DCs}$, compared to mice treated with cisplatin or the protein-based vaccine alone (Fig. 4B). Although we did not find differences in the frequency of DCs that express CD86 (Fig. 4C), DCs from mice treated with the chemo/immunotherapy or the protein-based vaccine alone showed higher expression of this costimulatory molecule, which correlate with a greater immune-stimulatory capacity (Fig. 4D). Similarly, mice treated with the combination of cisplatin and gDE7 admixed with pIC elicited increased frequency of $\mathrm{CD} 11 \mathrm{~b}^{+} \mathrm{F} 4 / 80^{+} \mathrm{MHCII}^{+}$macrophages compared to mice treated with cisplatin, protein-based vaccine alone or untreated mice (Fig. 4E). Besides that, the combined treatment did not increase the frequency of $\mathrm{CD}^{+} 6^{+}$intratumoral macrophages, but, otherwise, induced a higher CD86 expression in these cells, compared to mice submitted to the isolated treatments (Fig. 4F-G). The gating strategy applied in the analyses of these cell subsets is shown in Fig. S4.

In addition, we evaluated the frequency of $\mathrm{CD} 11 \mathrm{~b}^{+} \mathrm{Gr}-\mathrm{1}^{\text {high }}$ myeloid-derived suppressor cells (MDSCs) in mice submitted to the tested treatments. Our results revealed lower frequencies of intratumoral MDSCs in mice treated with cisplatin or protein-based vaccine alone, which was further reduced when cisplatin was combined with gDE7 admixed with pIC immunization (Fig. 5A). Treatment with cisplatin combined with the protein vaccine induced a significant increase in tumor-infiltrating $\mathrm{CD}^{+} \mathrm{T}$ cells (Fig. 5B), particularly antigen-specific $\mathrm{CD}^{+} \mathrm{T}$ cells, compared with mice treated with the protein-based vaccine alone (Fig. 5C). Antigenspecific $\mathrm{CD}^{+} \mathrm{T}$ cells, denoted Dex ${ }^{+} \mathrm{CD} 8{ }^{+} \mathrm{E} 7 \mathrm{~T}$ cells, represented $40 \%$ of the intratumoral $\mathrm{CD}^{+} \mathrm{T}$ cell population in mice submitted to the chemo/ immunotherapy (Fig. 5D). Altogether, these data demonstrate that administration of cisplatin and vaccination with gDE7 synergistically increases the frequency of tumor-infiltrating dendritic cells, macrophages, and antigen-specific $\mathrm{CD}^{+} \mathrm{T}$ cells, and reduces the frequency of intratumoral immunosuppressive cells.

\section{Combination of cisplatin and gD-based vaccines induces synergistic therapeutic effects in advanced tumors at different anatomical sites}

Tumors induced by HPV are found at different mucosal epithelia and may show distinct tumor microenvironments and immune surveillance mechanisms. To evaluate the therapeutic performance of the combined chemo/immunotherapy, we tested the treatment in an orthotopic tumor model after transplantation of TC-1 LUC cells into the vagina of the C57BL/6 mice, as an approach to simulate conditions found in human cervical and vaginal cancers. Tumor-bearing mice were first treated with a single cisplatin dose, followed by administration of two doses of the protein vaccine 10 days after the implantation of TC-1 LUC cells (Fig 6A), when tumor bioluminescence was approximately $10^{8}$ photons/second (Fig 6B). The results showed that administration of cisplatin or the protein-based vaccine alone induced partial control of tumor growth, leading to tumor regression in $25 \%$ and $30 \%$ of the mice, respectively (Fig 6C-D). Conversely, the combined treatment induced complete tumor regression in $90 \%$ of treated mice and $100 \%$ of survival during the observation period (Fig. 6D-E). Similar results were also observed in mice treated with cisplatin and the DNA vaccine pgDE7h (Fig. S5). Collectively, these data confirm the synergistic effects of the combined chemo/immunotherapy in HPV-associated tumors at the vaginal epithelium.

\section{Chemo/immunotherapy induces immunological memory responses and confers long-term protection from tumor relapses in different anatomical sites}

A key feature distinguishing passive immunotherapy approaches from those based on active immunotherapies (vaccines) is the induction of immunological memory to cancer-associated antigens. To examine the induction of immunological memory responses, mice were evaluated for long-term antitumor protection including the capacity of preventing tumor recurrence in different anatomical sites. For that purpose, mice bearing subcutaneous or intravaginal tumors were initially administered with the chemo/immunotherapeutic regimen. Tumor-free mice were subsequently re-challenged with a 10-fold higher load of TC-1 cells at the same anatomical site 60 days after the initial treatment. All mice administered with the combined treatment and re-challenged with TC-1 cells had induced high frequencies of circulating E7-specific IFN- $\gamma$-producing CD8 ${ }^{+} \mathrm{T}$ cells (Fig. 7A-B) and did not develop tumors (Fig. 7D-E). 

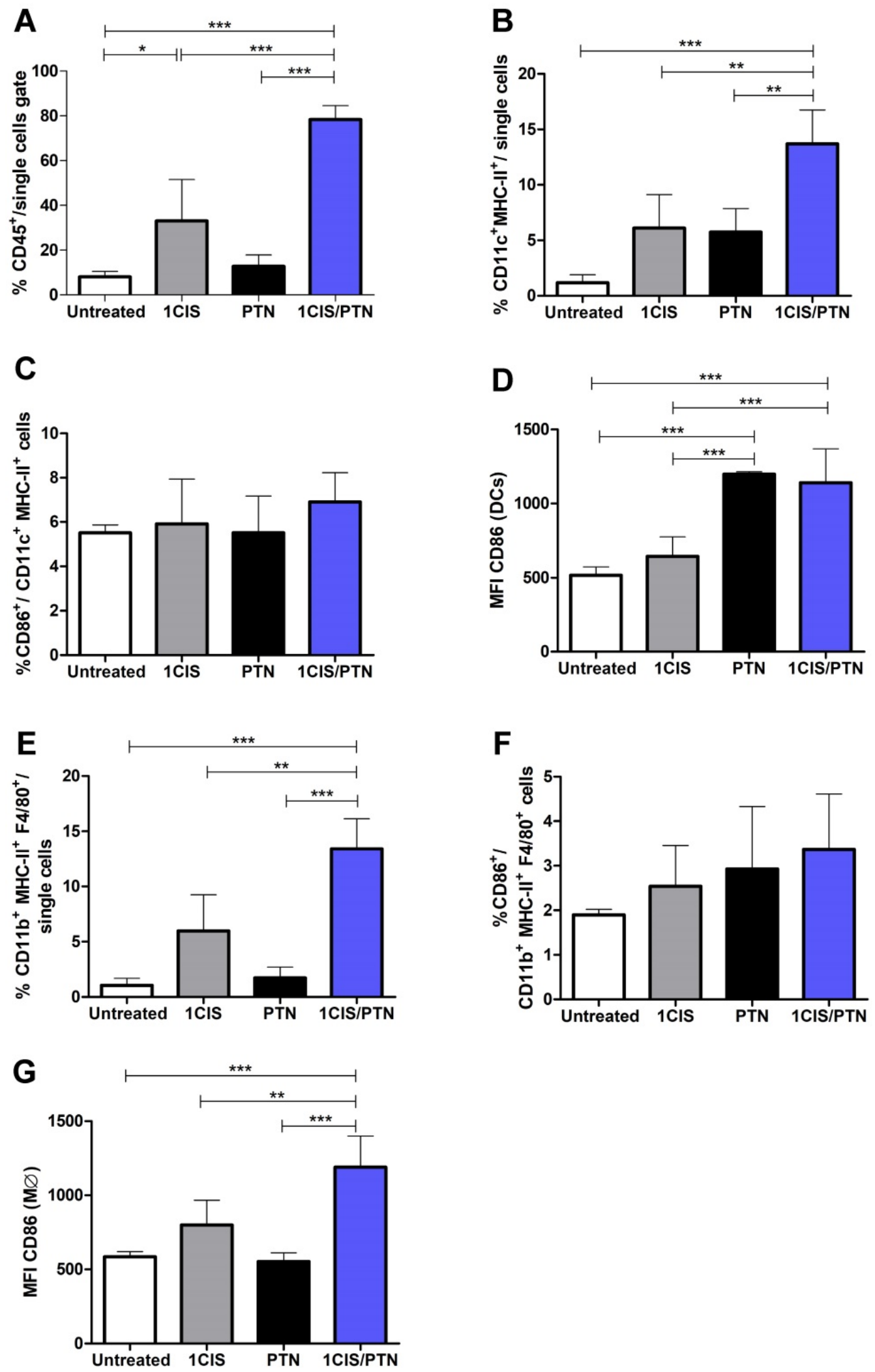

Figure 4: Immunization with purified gDE7 combined with cisplatin enhances tumor infiltration of antigen-presenting cells. Tumor-bearing C57BL/6 mice were treated with one dose of cisplatin, gDE7 admixed with poly $(\mathrm{l}: \mathrm{C})$ or cisplatin combined with gDE7 admixed with poly(l:C). Tumor samples were collected at day 10 and analyzed by flow cytometry. Frequency of (A) CD45+ infiltrating cells, (B) CD1 l c ${ }^{+} \mathrm{MHCll}^{+}$dendritic cells (DCs) and (C) CD1 lc ${ }^{+} \mathrm{MHCll}{ }^{+} \mathrm{CD} 86^{+}$activated DCs. (D) Median

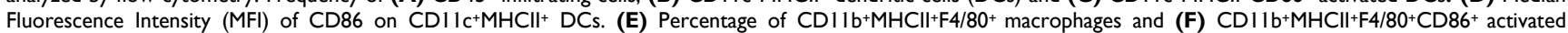
macrophages. (G) MFI of CD86 on CD1 lb+MHCll+F4/80+ macrophages. Gate strategies for detection of tumor-infiltrating antigen presenting cells are depicted in Figure 54 . Data are expressed as the mean + SD from one of two independent experiments with similar results $(n=3-5)$. ( $* *) P<0.01$, $(* * *) P<0.001$, as determined by one-way ANOVA followed by Bonferroni post hoc analysis. 

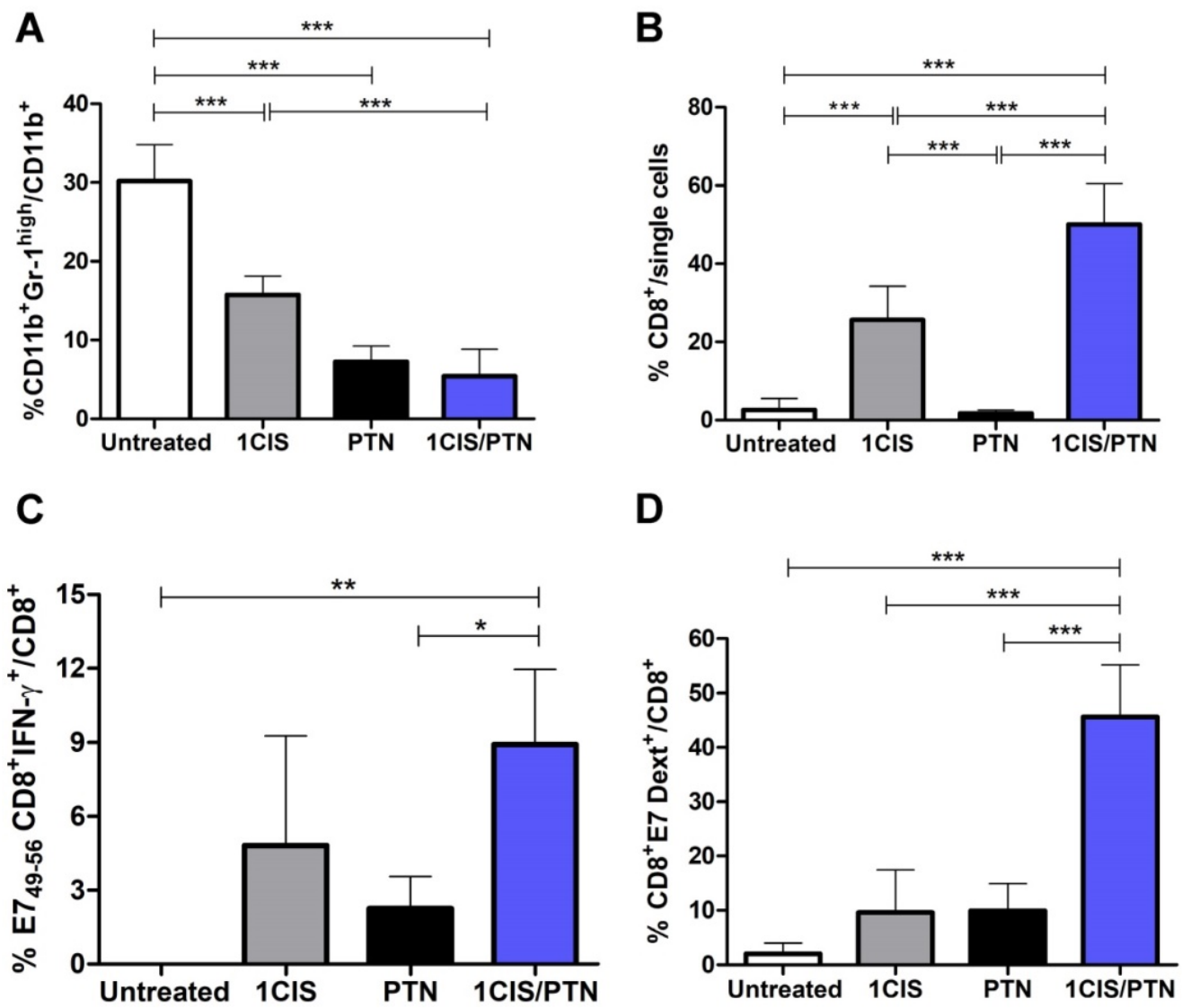

Figure 5: Administration of purified gDE7 and poly(I:C) combined with cisplatin reduces the frequency of myeloid suppressor cells and enhances tumor infiltration of E7-specific CD8+ T cells. Tumor-bearing C57BL/6 mice were treated with cisplatin, gDE7 admixed with poly (I:C) or the combined chemo/immunotherapy protocol. Tumor samples were obtained at day 10 and analyzed by flow cytometry. Frequency of (A) myeloid-derived suppressor cells (MDSCs) represented by CD1 $1 \mathrm{~b}+\mathrm{Gr}-1$ high cells, (B) CD8 ${ }^{+} \mathrm{T}$ cells, (C) IFN-Y+ CD8 ${ }^{+} \mathrm{T}$ cells after in vitro stimulation with the CD8-specific E7 peptide ( ${ }^{49}$ RAHYNIVTF57), and (D) E7-specific CD8 ${ }^{+} \mathrm{T}$ cells labeled with the E7 H-2Db-specific dextramer. Data are expressed as the mean + SD of one of two independent experiments with similar results $(n=5-6) .(*) P<0.05,(* *) P<0.01,(* * *) P<0.001$, as determined by one-way ANOVA followed by Bonferroni post hoc analysis.

We also evaluated if long-term tumor protection would also be detected at an anatomical site different from the initial site used to inoculate the TC-1 cells. For that purpose, mice with complete regression of primary intravaginal tumors were re-challenged with a 10-fold higher load of TC-1 LUC cells in the tongue. In these conditions, tumor re-challenged mice, at an anatomical site different from the primary tumor, showed enhanced frequencies of circulating E7-specific IFN- $\gamma$-producing $\mathrm{CD}^{+}{ }^{+} \mathrm{T}$ cells (Fig. 7C) and $90 \%$ of tumor rejection, remaining tumor-free until the end of the follow-up period (Fig.7F). Surviving mice were administered a second TC-1 LUC cells transplantation in the tongue two months later to assess the induced cellular responses. Spleen cells were collected two weeks after the second tumor cell challenge and tested for the presence of splenic antigen-specific $\mathrm{CD}^{+} \mathrm{T}$ cells (Fig. 7G), effector and central memory CD8 ${ }^{+} \mathrm{T}$ cells (Fig. 7H-I), and memory precursors (MPEC) and short-lived (SLEC) effector cells (Fig. 7J-K). Higher frequencies of MPEC, SLEC, and IFN-g ${ }^{+}$cells were detected among E7-specific effector $\mathrm{CD}^{+} \mathrm{T}$ cells in mice treated with chemo/immunotherapy. Collectively, our data show that cisplatin combined with gDE7 immunization led to long-term antitumor protection in mice. More relevantly, mice administered with the combined chemo/immunotherapy regimen were capable of preventing tumor relapses, experimentally simulated by re-challenge with TC- 1 cells at different epithelial sites. The long-term antitumor protection correlated with the activation of effector memory $\mathrm{CD}^{+} \mathrm{T}$ cells capable of migrating to peripheral tissues and responding to tumor cells.

\section{Discussion}

In this study, we demonstrated that combining active immunotherapy against HPV-associated tumors with cisplatin induces synergistic effects, promoting enhanced eradication of tumors at advanced growth stages and prevent tumor relapses with lower toxicity. Previous work from our group showed that the DNA or protein-based therapeutic vaccines tested here, comprising HPV-16 E7 genetically fused to HSV-1 $\mathrm{gD}$, led to enhanced activation of cytotoxic $\mathrm{CD} 8^{+}$. T cells and therapeutic 
effect in tumors during the initial stage of development $\quad[12,13,18,19]$. Combining immunotherapy with chemotherapy resulted in increased antitumor immune responses, involving activation of intratumoral antigen-specific $\mathrm{CD}^{+}$. $\mathrm{T}$ cells and APCs, with reduced frequencies of MDSCs. Importantly, the combined treatment generated more effective tumor protection at different anatomical sites, preventing tumor recurrence in subcutaneous, intravaginal, and tongue epithelia.
A

TC-1 IVAG

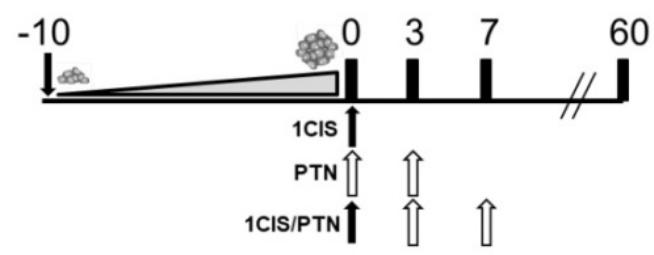

C

D0

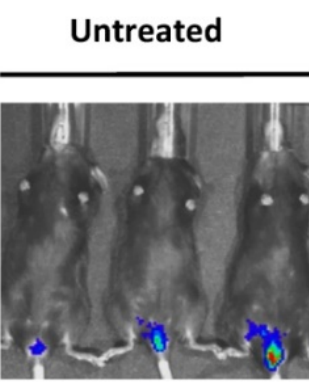

D14

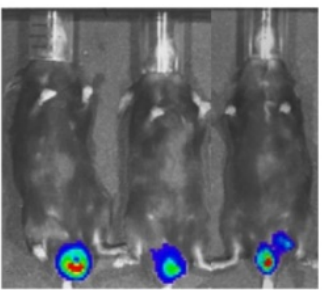

D

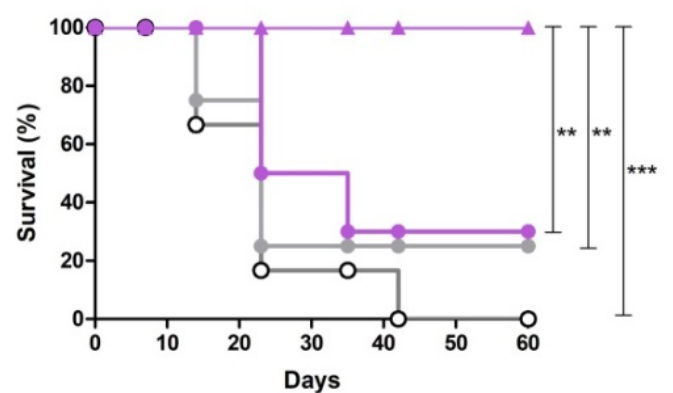

B

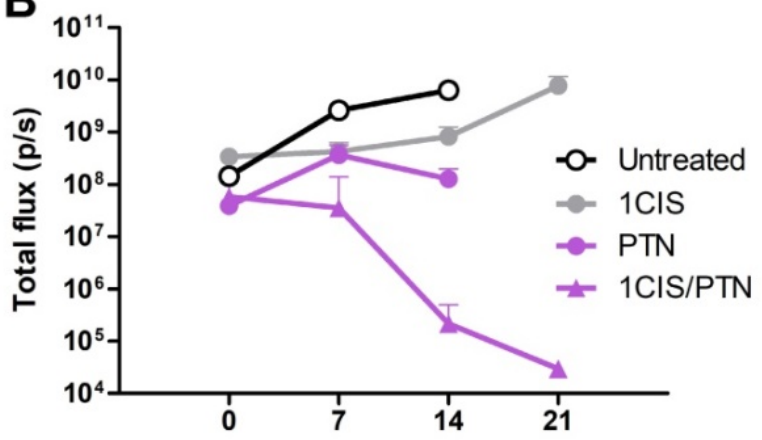

Days 1CIS/PTN
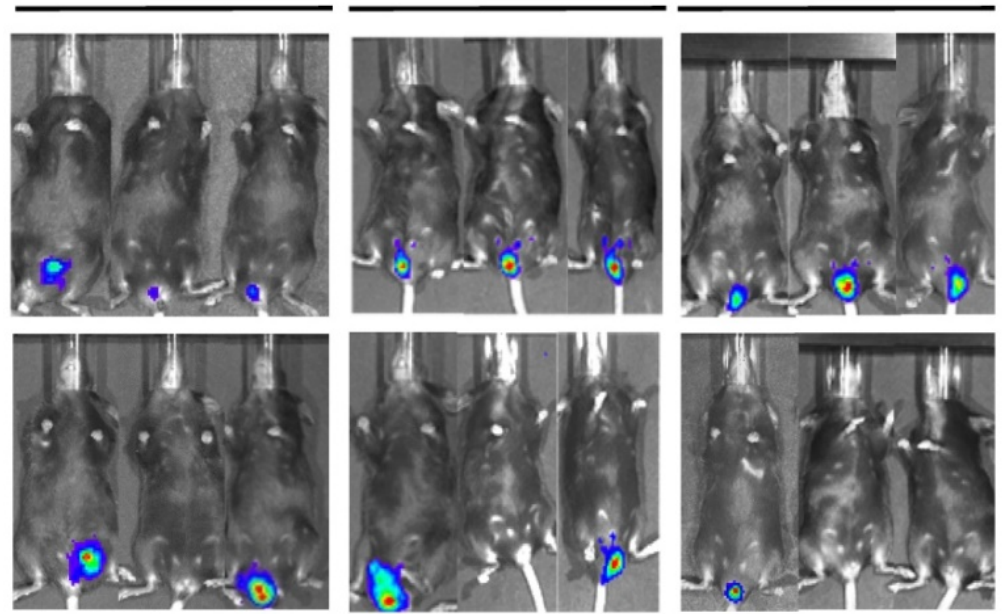

E

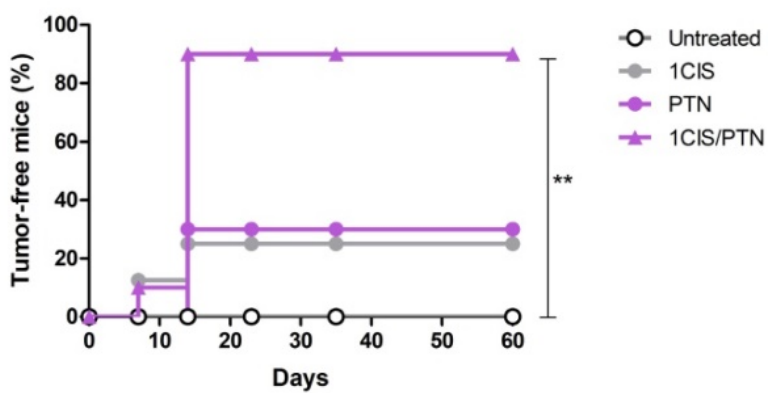

Figure 6: Combined treatment based on purified gDE7 admixed with poly(I:C) and cisplatin confers enhanced protection to intravaginal tumors. (A) Treatment representative sketch. C57BL/6 mice were inoculated with $10^{5} \mathrm{TC}-1$ LUC cells intravaginally and treated with one dose of cisplatin, gDE7 admixed with poly(l:C) or with the combined chemo/immunotherapy. Tumor growth was evaluated by bioluminescence emission. (B) Bioluminescence emissions from tumors measured as individual values of photons per second (p/s). (C) Representative bioluminescence images of vaginal TC-1 LUC tumors until day 14. (D) Percentage of survival, and (E) tumor-free mice followed until 60 days after the initial treatment. Data are expressed as the mean \pm SD of two independent combined experiments $(n=8-10)$. Statistical significance: $(* *) P<0.01$, (***) $P<0.001$, as determined by log-rank (Mantel-Cox) test. 
A
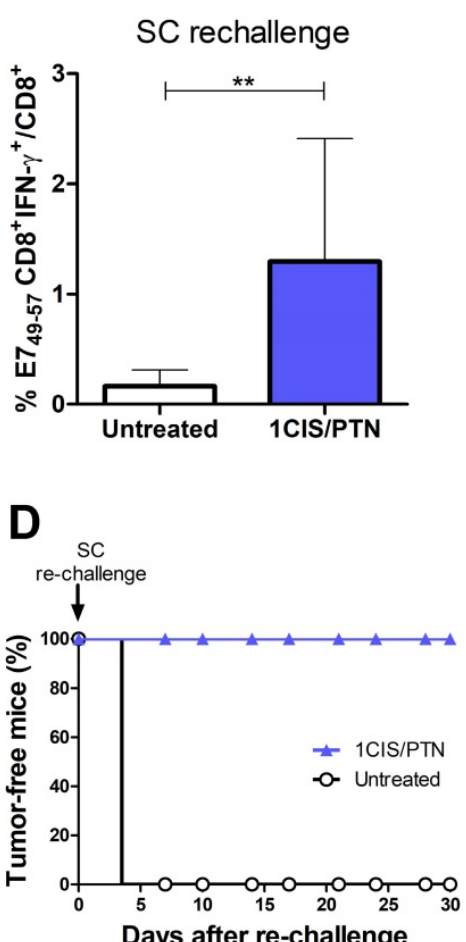

G

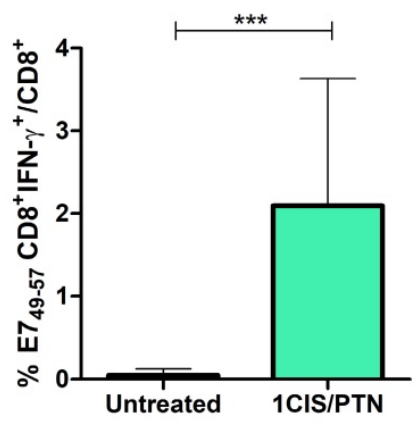

J
B

\section{IVAG rechallenge}

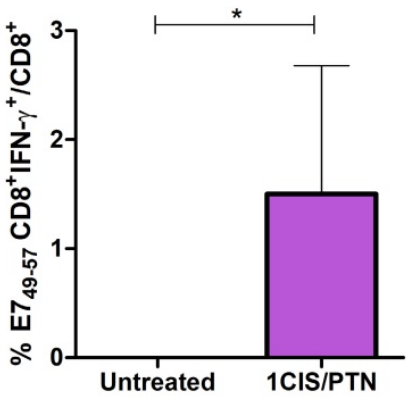

E

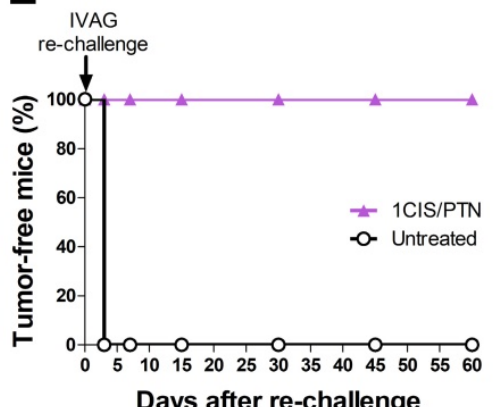

H

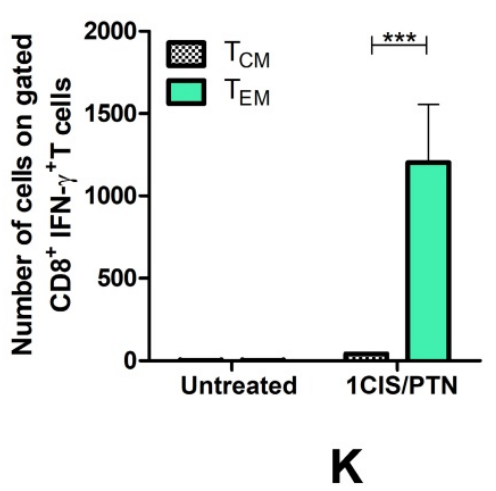

C

TONGUE rechallenge

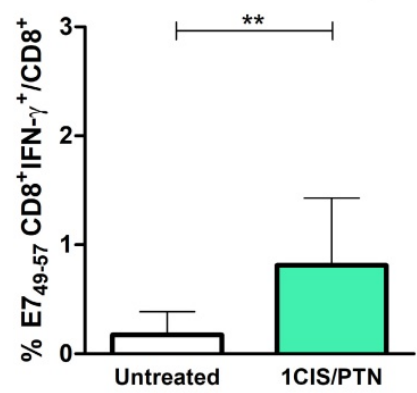

F

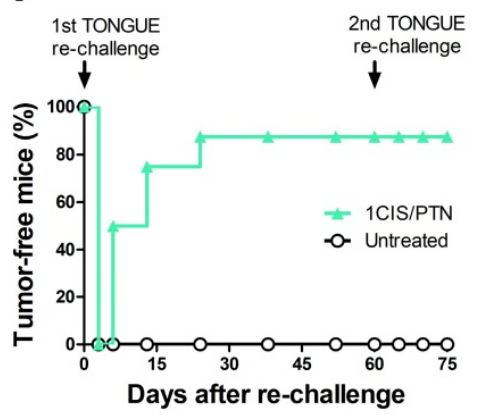

I
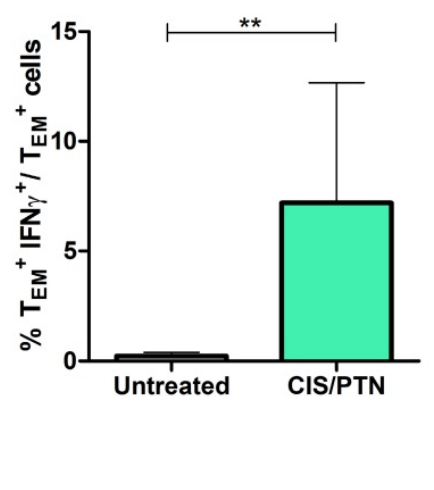
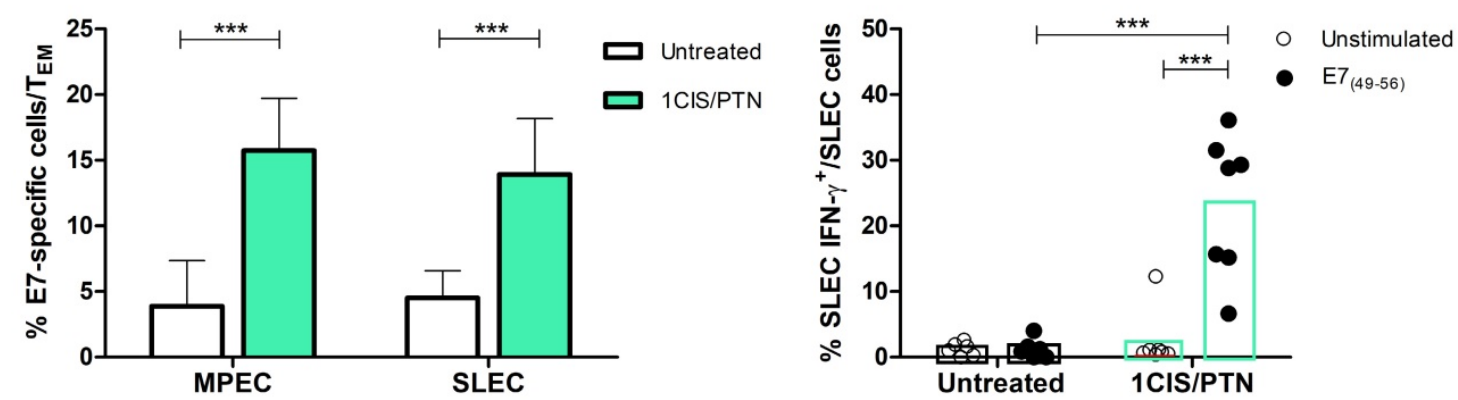

Figure 7: Combination of cisplatin and gDE7 admixed to poly(I:C) enhances the frequency of systemic tumor-specific CD8+ $T$ cells and prevents tumor relapses in different anatomical sites. C57BL/6 mice were inoculated with $10^{5} \mathrm{TC}-1$ cells and subsequently treated with the combined chemo/immunotherapy. At day 60 , tumor-free mice were rechallenged to simulate tumor relapses. Frequency of $C D 8^{+} I F N-\gamma^{+} / C D 8^{+} T$ cells after in vitro stimulation with the CD8-specific E7 peptide $\left({ }^{49}\right.$ RAHYNIVTF $\left.{ }^{57}\right)$ was determined seven days after: (A) subcutaneous, (B) intravaginal, and (C) intratongue reinoculation of $10^{6}$ TC-1 cells. Percentages of tumor-free mice after (D) subcutaneous, (E) intravaginal, or (F) intratongue reinoculation of TC-1 cells. Tumor-free mice of tongue rechallenge were subjected to a second tumor rechallenge with $10^{6}$ TC-1 cells at the same anatomical site. Spleens were collected 14 days after the second rechallenge and analyzed by flow cytometry. (G) Frequency of IFN- $\gamma^{+} \mathrm{CD} 8^{+} \mathrm{T}$ cells after in vitro stimulation with the CD8-specific E7 peptide ( ${ }^{49}$ RAHYNIVTF57). (H) Frequency of CD8 ${ }^{+} \mathrm{CD} 44+C D 62 L^{-}\left(T_{E M}\right)$, and $C D 8{ }^{+} C D 44+C D 62 L^{+}\left(T_{C M}\right)$ gated on CD8+IFN- $\gamma^{+} T$ cells, and (I) frequency of IFN- $\gamma^{+}$-expressing $T_{E M}$ cells. (J) Frequency of CD127-KLRG1+ $T_{E M}$ (SLEC) and CDI27+KLRG1- $T_{E M}(M P E C)$ splenic cells, and (K) IFN- $\gamma^{+}$-expressing SLEC $T_{E M}$ cells obtained after in vitro stimulation with or without the CD8 ${ }^{+} T$ cell-specific E7 peptide ( ${ }^{49}$ RAHYNIVTF57) from individual spleen samples. Data are expressed as the mean +SD of two independently performed experiments $(n=8-10)$. Statistical significance: $(*) P<0.05,(* *) P<0.01$, $(* * *) P<0.001$, as determined by two-way ANOVA or $t$-test. 
In humans, cervical cancer is the second most common cancer in Latin America and its mortality is projected to increase by $45 \%$ by 2030 despite HPV vaccination and screening efforts [20]. In general, patients with advanced-stage and metastatic disease continue to have a poor prognosis with response rates ranging from $35-50 \%$ with current therapeutic options [21]. The main goal of this work was to obtain an effective therapeutic protocol using active immunization that was able to eradicate tumors in an advanced growth stage. For this, we devised a treatment regimen that was initiated when the tumors reached diameters considered close to the limit of the preclinical model of tumors induced by HPV. In this protocol, we observed a slight control of tumor growth when using only protein or DNA-based vaccines; this was also observed in the group treated with only one dose of cisplatin. These results are better evidenced by observing the individual tumor growth curves for the non-combined treatments (Fig S1.), suggesting the potential of active immunization as a form of antitumor intervention. Of note, the inability of immunotherapy alone to reduce the tumor mass may be due to immunosuppression and difficulties in the infiltration of circulating cells in the tumor microenvironment, in addition to the increased proliferation. The combination with cisplatin, in turn, resulted in complete regression of tumors initially measuring $10 \mathrm{~mm}$ in diameter in almost $80 \%$ of mice treated with chemotherapy combined with the gDE7 vaccine. Similar studies have already been published with promising data on the combination of cisplatin with different immunotherapies against subcutaneous HPV-induced tumors. However, complete tumor regression occurred in non-established or only palpable tumors [22-26].

The benefits of this combination also include the reduction of at least one-third of the chemotherapy dose, and consequently, the elimination of deleterious effects triggered by weekly cisplatin doses. Cisplatin (cis-diamminedichloroplatinum or CDDP) is currently one of the most important cytostatic agents in treating a wide range of solid tumors, but the clinical usefulness of this drug is limited by the development of nephrotoxicity and hepatotoxicity, side-effects that may be produced in various animal models $[27,28]$. Alterations in kidney functions are characterized by signs of injury, such as changes in creatinine clearance and GSH status. GSH is the most important intracellular endogenous thiol used as a free radical scavenger to clear free radicals induced by CDDP, which maintains cell integrity by avoiding oxidative damage. Elevated GSH plays an important role in protecting CDDP-induced toxicity [29]. Our results revealed reduced GSH levels in mice treated with three doses of cisplatin. Nonetheless, enhanced levels of GSH in kidneys were shown in mice treated with cisplatin combined with both protein and DNA vaccines, which was not observed in the group treated with cisplatin alone (Fig. 2B). These data suggest protection from renal injury mainly using the protein vaccine, and the possible causes of this effect could be a subject of future investigations.

Although cisplatin is not considered a classical agent of immunogenic cell death, it induces HMGB1 release of tumor cells as shown previously, inducing the upregulation of costimulatory molecules on APCs intratumorally $[22,30]$. The recruitment of APCs also stimulates the uptake, processing, and presentation of dead cell-associated antigens, eventually resulting in the priming of an adaptive immune response [31]. In our work, we also demonstrated the capacity of combined treatment to enhance the CD86 expression in $\mathrm{CD}_{11} \mathrm{c}^{+} \mathrm{MHCII}^{+}$dendritic cells and $\mathrm{CD} 11 \mathrm{~b}^{+}$ $\mathrm{MHCII}^{+} \mathrm{F} 4 / 80^{+}$macrophages into the tumor, accompanied by a decrease in the number of CD $11 b^{+} G r-1^{\text {hi }}$ MDSCs. Several studies have already demonstrated the central role of $\mathrm{CD}^{+} \mathrm{T}$ cells in HPV-induced tumor control, either preclinical or clinical settings [32-36]. In general, no changes in absolute $\mathrm{T}$ cell count or substantial alterations in $\mathrm{CD}^{+}, \mathrm{CD}^{+}$, or regulatory $\mathrm{T}$ cells phenotype were observed, but enhanced IFN- $\gamma$-producing CD8 ${ }^{+} \mathrm{T}$ cell response was achieved after in vitro stimulation of E6/E7-specific peptides. Here, we showed high frequencies of IFN- $\gamma$-producing $\mathrm{CD} 8^{+} \mathrm{T}$ cell reaching almost half the percentage of E7-specific lymphocytes within the total $\mathrm{CD}^{+} \mathrm{T}$ cell population in the tumor. As expected, most mice treated with cisplatin combined with either DNA or protein-based immunotherapies showed a complete tumor remission, even after subsequent TC-1 cells transplantations, indicating the potential of the combined treatment to induce a memory response.

Previous studies have found an increased risk of $\mathrm{HPV}$-associated second primary cancers (SPCs), especially oropharyngeal HPV-SPCs, among cervical cancer survivors [37-40]. Meanwhile, developed immunotherapeutic approaches targeting HPV oncogenes were very effective in inducing regression of established tumors in animal models, but the results strongly contrasted the poor clinical outcome to date. One possible cause of this discrepancy is represented by the non-orthotopic localization of the experimental tumor [41]. Although many HPV-induced cancers are located in mucosal sites, most cancer immunotherapies were tested against SC tumors in preclinical settings [42]. In this context, the submucosal administration of HPV-16 E7-expressing tumor cells in the cervicovaginal tract was previously 
described $[43,44]$ and represents a useful way to mitigate the discrepancy between preclinical and clinical outcomes. Here, we showed the synergistic phenomenon between cisplatin and our therapeutic vaccines after implantation of mucosal tumors using the same parenteral vaccination regimen. For both protein and DNA-based vaccines, we observed 100\% survival and $90 \%$ tumor regression in mice primarily carrying intravaginal tumors. In addition, all cured mice rejected a second tumor implantation in the intravaginal site. Interestingly, we evaluated the capacity of cisplatin combined with protein-based immunotherapy to prevent tumor recurrences after subsequent tumor cell transplantations in the tongue of mice that had been previously treated for an intravaginal tumor. Our results showed that $90 \%$ of mice clearly rejected the secondary developing tumor. This protection was accompanied by the enrichment of E7-specific CD8 ${ }^{+} \mathrm{T}$ cells systemically, particularly effector memory $\mathrm{T}$ cell subsets, which play an important role in antitumor immunosurveillance.

\section{Conclusions}

The present work demonstrated a potent treatment for HPV-associated tumors involving cisplatin and two active immunotherapeutic strategies based on either DNA or protein-based vaccines. The observed outcomes were a consequence of the induction of an effector memory $\mathrm{T}$ cell response, both locally and systemically, as demonstrated by our rechallenge experiments. This study presents relevant experimental evidence that shall be tested under clinical conditions, in which patients treated with the combined therapy and undergoing tumor remission could be protected against any local or distant site relapses. Altogether, the evidence indicated that the chemo-vaccination strategy proposed here is a promising approach for the treatment of HPV-associated cancer likely to be further evaluated in an early-phase clinical trial.

\section{Abbreviations}

ALT: alanine aminotransferase; ANOVA: analysis of variance; APC: antigen-presenting cell; AST: aspartate aminotransferase; BUN: blood urea nitrogen; CDDP: cis-diamminedichloroplatinum; DC: dendritic cell; EGFR: epidermal growth factor receptor; FBS: fetal bovine serum; gD: glycoprotein D; GSH: glutathione; GSSG: oxidized glutathione; HSV-1: herpes simplex virus 1; IGFR: insulin-like growth factor receptor; H\&E: hematoxylin and eosin; HPV: human papillomavirus; IM: intramuscular; IV: intravenous; mAbs: monoclonal antibodies; MDSC: myeloid-derived suppressor cell; MPEC: memory precursors effector cell; PBS: phosphate buffered saline; MФ: macrophage; pIC: poly(I:C); SC: subcutaneous; SLEC: short-lived effector cell; SPC: second primary cancer; US FDA: United States Food and Drug Administration.

\section{Supplementary Material}

Supplementary figures and table. https://www.ijbs.com/v18p0015s1.pdf

\section{Acknowledgments}

The authors greatly appreciate the helpful technical support of EG Martins of the Vaccine Development Laboratory, University of São Paulo.

\section{Author Contributions}

The results presented in the work were obtained by the authors and their respective contributions: BFMM Porchia, LRMM Aps, ACR Moreno, MO Diniz and LCS Ferreira: conception and design, development of methodology, acquisition, analysis and interpretation of data, writing and revision of the manuscript, material support. The other authors participated in the acquisition, analysis and interpretation of data.

\section{Funding}

This work was supported by Fundação de Amparo à Pesquisa do Estado de São Paulo (FAPESP), LRMM Aps, grants 2020/13640-1 and 2018/08502-9, and ACR Moreno, grant 2015/16505-0. BFMM Porchia was a fellow from FAPESP 2011/20917-0, 2017/21358-1 and PNPD CAPES. LRMM Aps was a fellow from FAPESP 2011/13805-1 and 2013/15360-2.

\section{Competing Interests}

LRMM. Aps, BFMM Porchia, and MO Diniz hold ownership interest (including patents) in ImunoTera Soluções Terapêuticas Ltda. No potential conflicts of interest were disclosed by the other authors.

\section{References}

1. Brisson M, Kim JJ, Canfell $\mathrm{K}$, et al. Impact of HPV vaccination and cervical screening on cervical cancer elimination: a comparative modelling analysis in 78 low-income and lower-middle-income countries. Lancet . 2020; 395: 575-90.

2. Bray F, Ferlay J, Soerjomataram I, Siegel RL, Torre LA, Jemal A. Global cancer statistics 2018: GLOBOCAN estimates of incidence and mortality worldwide for 36 cancers in 185 countries. CA: CA Cancer J Clin. 2018; 68: 394-424.

3. Arbyn M, Weiderpass E, Bruni L, et al. Estimates of incidence and mortality of cervical cancer in 2018: a worldwide analysis. Lancet Glob Health. 2020; 8: e191-203.

4. Gillison ML, Castellsagué X, Chaturvedi A, et al. Eurogin Roadmap: Comparative epidemiology of HPV infection and associated cancers of the head and neck and cervix. Int J Cancer. 2014; 134: 497-507.

5. Shewale JB, Gillison ML. Dynamic factors affecting HPV-attributable fraction for head and neck cancers. Curr Opin Virol. 2019; 39:33-40.

6. Sankaranarayanan R, Swaminathan R, Brenner H, et al. Cancer survival in Africa, Asia, and Central America: a population-based study. Lancet Oncol. 2010; 11: 165-73.

7. Falcetta FS, Medeiros LR, Edelweiss MI, Pohlmann PR, Stein AT, Rosa DD. Adjuvant platinum-based chemotherapy for early stage cervical cancer. Cochrane Database Sys Rev. 2016; 11:CD005342. 
8. Rosa DD, Medeiros LR, Edelweiss MI, Pohlmann PR, Stein AT. Adjuvant platinum-based chemotherapy for early stage cervical cancer. Cochrane Database of Sys Rev. 2012; 6: CD005342.

9. Gravbrot, Gilbert-Gard, Mehta, et al. Therapeutic Monoclonal Antibodies Targeting Immune Checkpoints for the Treatment of Solid Tumors. Antibodies. 2019; 8: 51 .

10. Tewari KS, Sill MW, Penson RT, et al. Bevacizumab for advanced cervical cancer: final overall survival and adverse event analysis of a randomised, controlled, open-label, phase 3 trial (Gynecologic Oncology Group 240). Lancet. 2017; 390: 1654-63.

11. Chung HC, Ros W, Delord JP, et al. Efficacy and safety of pembrolizumab in previously treated advanced cervical cancer: Results from the phase II KEYNOTE-158 study. J Clin Oncol. 2019; 37: 1470-8.

12. Diniz MO, Cariri FAMO, Aps LRMM, Ferreira LCS. Enhanced therapeutic effects conferred by an experimental DNA vaccine targeting human papillomavirus-induced tumors. Hum Gene Ther. 2013; 24: 861-70.

13. Porchia BFMM, Diniz MO, Cariri FAMO, et al. Purified herpes simplex type 1 glycoprotein $\mathrm{D}(\mathrm{gD})$ genetically fused with the type 16 human papillomavirus E7 oncoprotein enhances antigen-specific CD8 + T cell responses and confers protective antitumor immunity. Mol Pharm. 2011; 8: 2320-30.

14. Lin KYKY, Guarnieri FGFG, Staveley-O'Carroll KFF, et al. Treatment of Established Tumors with a Novel Vaccine That Enhances Major Histocompatibility Class II Presentation of Tumor Antigen. Cancer Res. 1996; 56: 21-6.

15. Kim D, Hung C-F, Wu T-C. Monitoring the Trafficking of Adoptively Transferred Antigen- Specific CD8-Positive T Cells In vivo , Using Noninvasive Luminescence Imaging. Human Gene Ther. 2007; 18: 575-88.

16. Feltkamp MC, Smits HL, Vierboom MP, et al. Vaccination with cytotoxic T lymphocyte epitope-containing peptide protects against a tumor induced by human papillomavirus type 16-transformed cells. Eur J Immunol. 1993; 23: 2242-9.

17. Sales NS, Silva JR, Aps LRMM, et al. In vivo electroporation enhances vaccine-mediated therapeutic control of human papilloma virus-associated tumors by the activation of multifunctional and effector memory CD8 ${ }^{+} \mathrm{T}$ cells. Vaccine. 2017; 35: 7240-9.

18. Porchia BFMM, Moreno ACR, Ramos RN, et al. Herpes simplex virus glycoprotein $\mathrm{D}$ targets a specific dendritic cell subset and improves the performance of vaccines to human papillomavirus-associated tumors. Mol Cancer Ther. 2017; 16: 1922-33.

19. Diniz MO, Sales NS, Silva JR, Ferreira LCS. Protection against HPV-16-Associated tumors requires the activation of CD8+ effector memory $\mathrm{T}$ cells and the control of myeloid-derived suppressor cells. Mol Cancer Ther. 2016; 15: 1920-30.

20. Bychkovsky BL, Ferreyra ME, Strasser-Weippl K, et al. Cervical cancer control in Latin America: A call to action. Cancer. 2016; 122(4):502-14.

21. Ring KL, Yemelyanova A V., Soliman PT, Frumovitz MM, Jazaeri AA. Potential immunotherapy targets in recurrent cervical cancer. Gynecol Oncol. 2017; 145: 462-8.

22. Nejad EB, Van Der Sluis TC, Van Duikeren S, et al. Tumor eradication by cisplatin is sustained by CD80/86-mediated costimulation of $\mathrm{CD}^{+} \mathrm{T}$ cells. Cancer Res. 2016; 76: 6017-29.

23. Kang TH, Mao C, Lee SY, Chen A, Lee J, Kim TW. Chemotherapy Acts as an Adjuvant to Convert the Tumor Microenvironment into a Highly Permissive State for Vaccination-Induced Antitumor Immunity. Cancer Res. 2013; $2493-$ 505.

24. Lee SY, Kang TH, Knoff J, et al. Intratumoral injection of therapeutic HPV vaccinia vaccine following cisplatin enhances HPV-specific antitumor effects. Cancer Immunol, Immunoth. 2013; 62: 1175-85.

25. Peng S, Wang JW, Karanam B, et al. Sequential Cisplatin Therapy and Vaccination with HPV16 E6E7L2 Fusion Protein in Saponin Adjuvant GPI-0100 for the Treatment of a Model HPV16 + Cancer. Plos One. 2015; 10: 125 .

26. Tseng CW, Hung CF, Alvarez RD, et al. Pretreatment with cisplatin enhances E7-Specific CD8 ${ }^{+}$T-cell -mediated antitumor immunity induced by DNA vaccination. Clin Cancer Res. 2008; 14: 3185-92.

27. Atessahin A, Yilmaz S, Karahan I, Ceribasi AO, Karaoglu A. Effects of lycopene against cisplatin-induced nephrotoxicity and oxidative stress in rats. Toxicology. 2005; 212: 116-23.

28. Cepeda V, Fuertes M, Castilla J, Alonso C, Quevedo C, Perez J. Biochemical Mechanisms of Cisplatin Cytotoxicity. Anti-Cancer Agents Med Chem. 2008; 7: 3-18.

29. Gong C, Qian L, Yang H, et al. Hepatotoxicity and pharmacokinetics of cisplatin in combination therapy with a traditional Chinese medicine compound of Zengmian Yiliu granules in ICR mice and SKOV-3-bearing nude mice. BMC Complement Altern Med. 2015; 15:283.

30. Galluzzi L, Buqué A, Kepp O, Zitvogel L, Kroemer G. Immunogenic cell death in cancer and infectious disease. Nat Rev Immunol. 2017; 17(2):97-111.

31. Bezu L, Gomes-da-Silva LC, Dewitte H, et al. Combinatorial strategies for the induction of immunogenic cell death. Front Immunol. 2015; 6:187.

32. Bagarazzi ML, Yan J, Morrow MP, et al. Immunotherapy Against HPV16/18 Generates Potent TH1 and Cytotoxic Cellular Immune Responses. Science Translational Medicine. 2012; 4: 155ra138-155ra138.

33. van Poelgeest MIE, Welters MJP, van Esch EMG, et al. HPV16 synthetic long peptide (HPV16-SLP) vaccination therapy of patients with advanced or recurrent HPV16-induced gynecological carcinoma, a phase II trial. J Transl Med. 2013; 11:88

34. Trimble CL, Morrow MP, Kraynyak KA, et al. Safety, effi cacy, and immunogenicity of VGX-3100, a therapeutic synthetic DNA vaccine targeting human papillomavirus 16 and $18 \mathrm{E} 6$ and E7 proteins for cervical intraepithelial neoplasia 2 / 3 : a randomised, double-blind, placebo-controlled phase $2 \mathrm{~b}$. Lancet. 2015; 386(10008):2078-2088.

35. Kim TJ, Jin H-T, Hur S-Y, et al. Clearance of persistent HPV infection and cervical lesion by therapeutic DNA vaccine in CIN3 patients. Nat Commun. 2014; 5: 5317.

36. Welters MJ. Vaccination during myeloid cell depletion by cancer chemotherapy fosters robust T-cell responses. Sci Transl Med. 2016; 8(334):334ra52.

37. Suk R, Mahale P, Sonawane $\mathrm{K}$, et al. Trends in Risks for Second Primary Cancers Associated With Index Human Papillomavirus-Associated Cancers. JAMA Netw Open. 2018; 1: e181999.

38. Arnold M, Liu L, Kenter GG, Creutzberg CL, Coebergh JW, Soerjomataram I. Second primary cancers in survivors of cervical cancer in the Netherlands: Implications for prevention and surveillance. Radiother Oncol. 2014; 111: 37481.

39. Balamurugan A, Ahmed F, Saraiya M, et al. Potential role of human papillomavirus in the development of subsequent primary in situ and invasive cancers among cervical cancer survivors. Cancer. 2008; 113: 2919-25.

40. Chaturvedi A, Engels E, Gilbert E, et al. Second cancers among 104,760 survivors of cervical cancer: evaluation of long-term risk. J Natl Cancer Inst. 2007; 99(21):1634-43

41. Paolini F, Massa S, Manni I, Franconi R, Venuti A. Immunotherapy in new pre-clinical models of HPV-associated oral cancers. Hum Vaccin and Immunother. 2013; 9(3):534-43.

42. Sandoval F, Terme M, Nizard M, et al. Mucosal imprinting of vaccine-induced $\mathrm{CD}^{+} \mathrm{T}$ cells is crucial to inhibit the growth of mucosal tumors. Sci Transl Med. 2013; 5(172):172ra20.

43. Soong RS, Song L, Trieu J, et al. Toll-like receptor agonist imiquimod facilitates antigen-specific $\mathrm{CD} 8{ }^{+} \mathrm{T}$-cell accumulation in the genital tract leading to tumor control through IFNy. Clin Cancer Res. 2014; 20: 5456-67.

44. Sun Y, Peng S, Qiu J, et al. Intravaginal HPV DNA vaccination with electroporation induces local $\mathrm{CD} 8{ }^{+} \mathrm{T}$-cell immune responses and antitumor effects against cervicovaginal tumors. Gene Ther. 2015; 22: 528-35. 